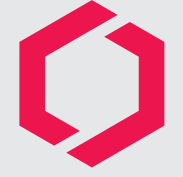

SCS

\title{
Nachruf
}

\section{Dr. Andreas Mühlebach}

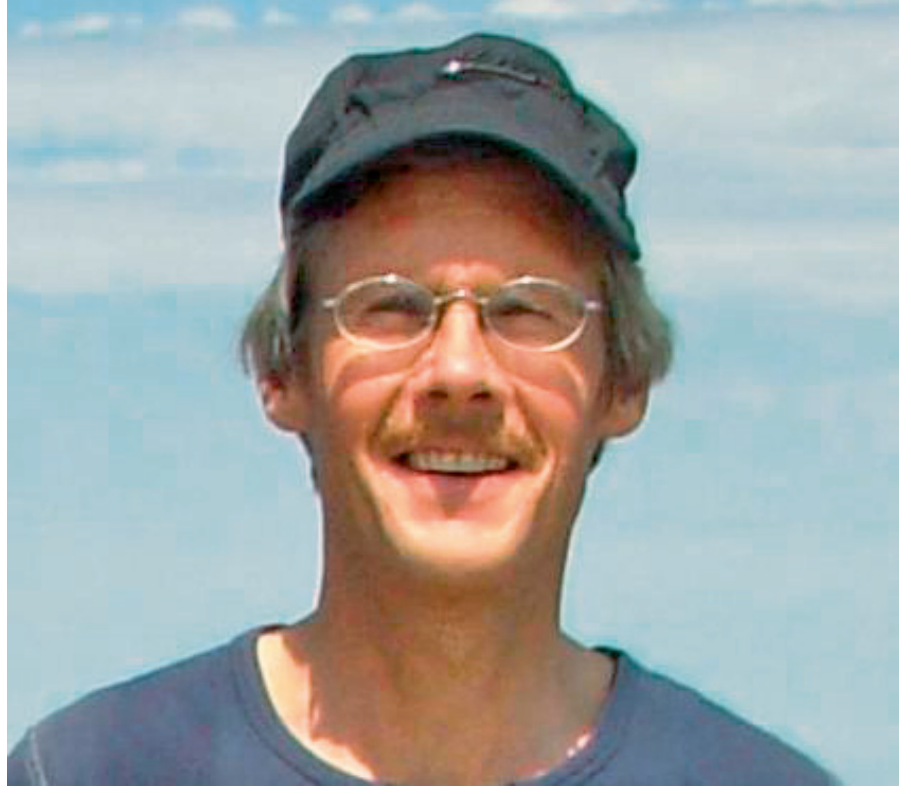

Mit grossem Schmerz müssen wir bekanntgeben, dass unser Kollege Dr. Andreas Mühlebach zusammen mit seiner Frau und seiner Tochter am 6. Juli 2010 in den Berner Alpen tödlich verunglückt ist. Wir sind erschüttert und tieftraurig. Andreas war Vorstandsmitglied und Quästor der SCG-Division Polymere und Kolloide. Er hinterlässt zwei Söhne, Michael und Florian, denen wir unser herzliches Beileid aussprechen.

Nach der Matura an der Kantonsschule Baden im Jahr 1977 nahm Andreas das Chemiestudium an der ETH Zürich auf, das er 1981 als Diplom-Chemiker abschloss. Neben seiner Tätigkeit als Chemielehrer an der Kantonsschule Aarau führte er von 1982 bis 1986 eine Dissertation über konstitutionelle Isomerie in Polyamiden bei Professor Piero Pino an der ETH durch.

Andreas verbrachte zwei Jahre als Postdoc am Almaden Research Center der IBM in San Jose, Kalifornien, wo er an Synthese, Charakterisierung und Anwendungen von flüssigkristallinen Polymeren arbeitete. Nach weiteren neun Monaten als Assistent an der ETH bei Professor Pino trat er 1989 ins damalige Forschungszentrum von Ciba-Geigy in Marly ein.

Die ersten drei Jahre beschäftigte er sich mit der Entwicklung von Klebstoffen auf Epoxy- und Polyurethanbasis. Von 1992 bis 1997 war er Mitglied der Zentralen Forschung von Ci-

ba und arbeitete an neuen Photopolymer-Systemen, Hydrogelen und thermischer sowie photoinduzierter Ringöffnungs-Metathese-Polymerisation. Er war Teil eines Teams, dem 1998 der Sandmeyer-Preis der SCG für die Entwicklung neuer photovernetzbarer Hydrogele für Kontaktlinsen verliehen wurde.

Nach einem dreimonatigen Sabbatical an der Carnegie Mellon Univesity in Pittsburgh bei Professor Krzysztof Matyjaszewski wechselte Andreas 1998 in die Ciba-Division Additive in Basel und leitete verschiedene Projekte zur Entwicklung von polymeren Additiven und neuen funktionellen Materialien. Die Projekte wurden teilweise in Zusammenarbeit mit der ETH und dem Max-Planck-Institut für Polymerforschung in Mainz durchgeführt. 2003 wurde er zum „Ciba Research Fellow“, 2005 zum „Ciba Senior Research Fellow“ befördert.

Seit 2005 war Andreas Vorstandsmitglied der damaligen Polymergruppe Schweiz. Ab 2007 war er Quästor der neu gegründeten Division Polymere und Kolloide der SCG. In seiner Freizeit war Andreas ein passionierter Bergsteiger und erfahrener Tourenleiter. Mit seiner Familie unternahm er sehr viele Kletterund Skitouren.

Andreas hatte auf Ende Juli 2010 seine inzwischen zur BASF Schweiz gehörende Stelle gekündigt, um eine neue Herausforderung als Professor an der Zürcher Hochschule für Angewandte Wissenschaften in Winterthur anzunehmen. Er hatte sich sehr auf diese neue Aufgabe gefreut und sich schon intensiv darauf vorbereitet.

Andreas war nicht nur ein ausgezeichneter und kreativer Chemiker, er war uns auch ein sehr guter Kollege und Freund. Mit seiner positiven, offenen und fröhlichen Art verbreitete er Optimismus und motivierte Mitarbeiter und Kollegen. Alle Projekte, die er in Angriff nahm, bearbeitete er mit Überzeugung und Elan. Es war eine Freude, im Vorstand der Division Polymere und Kolloide mit ihm zusammenzuarbeiten. Sein herzliches Lachen wird uns fehlen.

Den Söhnen Michael und Florian und allen weiteren Angehörigen wünschen wir viel Kraft und Mut, um mit ihrem Verlust fertig zu werden.

Bettina Steinmann Division Polymere und Kolloide der SCG
Peter Kündig

Schweizerische Chemische Gesellschaft 